\title{
A Morphometric Analysis of Functionally Defined Subpopulations of Neurons in the Paraventricular Nucleus of the Rat with Observations on the Effects of Colchicine
}

\author{
J.-H. Rho' and L. W. Swanson ${ }^{1,2}$ \\ 'Neural Systems Laboratory, The Salk Institute for Biological Studies, La Jolla, California 92037, and ${ }^{2}$ Howard Hughes \\ Medical Institute, Bethesda, Maryland 20817
}

Two populations of neurons in the paraventricular nucleus of the hypothalamus that have different efferent projections and physiological roles in the regulation of visceral responses were characterized morphologically with a combined intracellular filling, retrograde tracer, and immunohistochemical method. Neuroendocrine cells were retrogradely labeled by an intravenous injection of Fast blue, and distinguished from descending neurons that were retrogradely labeled by an injection of fluorogold into the spinal cord. Retrogradely labeled neurons were selectively penetrated and filled intracellularly with Lucifer yellow to visualize detailed features of their morphology. Corticotropin-releasing hormone ( $\mathrm{CRH}$ )-containing neurons were distinguished from other neuroendocrine cells by immunostaining the tissue with an antiserum to rat CRH. Morphometric features of defined populations of neurons were then quantified and reconstructed graphically to generate multicellular montage drawings that demonstrate their spatial organization. Descending neurons were further separated into dorsal and ventral medial parvicellular components, while the neuroendocrine population was differentiated into parvicellular and magnocellular groups. The mean somal areas, total dendritic lengths, and spine densities were compared between groups of neurons, and these showed significant differences across cell types. These measures were also dramatically affected by colchicine, which appears to induce the formation of new dendritic appendages, swelling of the soma, and reduction of dendritic length. Whether colchicine is acting directly upon cytoskeletal structures or indirectly by altering the physiology of the cell is unclear. However, the precise effects of colchicine on mean somal area, total dendritic length, and spine density appear to be dependent upon individual cell type. Colchicine may therefore act in a nonspecific, but nonetheless highly selective, manner in disrupting an endogenous mechanism regulating the number, morphology, and location of spines.

\footnotetext{
Received June 6, 1988; revised Aug. 15, 1988; accepted Aug. 25, 1988.
}

This work was supported in part by NIH Grant R1NS16686C and by the Rice Foundation. We thank Dr. D. A. Brittain for help with the computer system, Mr. $\mathrm{K}$. Trulock for photographic assistance, and Mr. D. Warren for preparing the manuscript.

Correspondence should be addressed to I. W. Swanson, The Neural Systems Laboratory, The Salk Institute, P.O. Box 85800, San Diego, CA 92138-9216.

Copyright (C) 1989 Society for Neuroscience $0270-6474 / 89 / 041375-14 \$ 02.00 / 0$
The paraventricular nucleus of the hypothalamus (PVII) contains a heterogenous population of neurons that have been differentiated on the basis of their neuropeptide content and on their patterns of afferent and efferent connections (see Swanson and Sawchenko, 1983; Swanson et al., 1986, 1987, for reviews). Two classes of neuroendocrine cells are found in the nucleus. One class consists of magnocellular cells that release oxytocin or vasopressin into the general circulation at the level of the posterior pituitary, while the other consists of parvicellular neurons that secrete hormones into the hypophyseal portal system to influence in turn the secretion of anterior pituitary hormones. These neurons together provide an interface between the CNS and the endocrine system, translating neural information into a physiological code that consists of blood-borne factors. Parvicellular neurons that contain corticotropin-releasing hormone (CRH), for example, have a specialized function since they play a major rolc in regulating the sccretion of ACTH from the anterior pituitary, and are therefore involved in mediating adrenal glucocorticoid responses to a wide variety of stressors. These CRH neurons are highly complex in the sense that they may also express many other neuoactive peptides, including vasopressin, angiotensin, enkephalin, neurotensin, and cholecystokinin, and the ratios of these peptides are altered by circulating levels of glucocorticoids. Descending neurons in the PVH, on the other hand, send axons to the brain stem and spinal cord that are presumably involved in coordinating both sympathetic and parasympathetic, as well as somatomotor responses, with endocrine activity.

The PVH is, however, anatomically compartmentalized, with descending and neuroendocrine cells segregated largely, though not completely, within separate parts of the nucleus. Most descending neurons, for example, are distributed in distinct clusters that have been called the dorsal (dp), ventral medial (mpv), and lateral (lp) parvicellular parts of the PVH (Swanson and Kuypers, 1980). Magnocellular neurons are clustered in 3 densely packed nuclear groups that can be distinguished in Nisslstained material by their density and the size of their somata. Parvicellular neurosecretory neurons, on the other hand, are centered in the dorsal medial parvicellular (mpd) and periventricular (pv) parts of the PVH, which contain a more heterogeneous profile of morphologically and immunohistochemically defined cell types, including those synthesizing $\mathrm{CRH}$, thyrotropin-releasing hormone (TRH), growth hormone-releasing hormone (GRH), and dopamine.

Despite this anatomical compartmentalization, neuroendocrine, autonomic and somatomotor responses to particular stim- 
uli require integrated neurological activity that must be coordinated between and within these neuronal populations. In the present study, we have analyzed the spatial relationships and morphological features of several neuroanatomically distinguishable cell types within the PVH using immunohistochemical and retrograde labeling methods combined with an intracellular filling technique (Rho and Swanson, 1987). In 100- $\mu \mathrm{m}-$ thick paraformaldehyde-fixed tissue sections through the PVH, rctrogradely labeled descending or neuroendocrine cells were selectively penetrated and intracellularly filled with Lucifer yellow (LY). Tissue sections were then processed for immunohistochemistry to distinguish $\mathrm{CRH}$-immunoreactive cells from other neuroendocrine cells. Finally, with computer graphics methods, their morphological features were quantified and compared to characterize differences between defined groups of neurons.

\section{Materials and Methods}

Neuroanatomical staining. To differentiate descending from neuroendocrine cell types in the PVH, $0.8 \mathrm{ml}$ of a $0.25 \%$ aqueous solution of Fast blue (Dr. Illig GmBH and Co., Grob-Umstadt, Germany) was injected into the tail vein of 38 adult male rats (Sprague-Dawley), and pellets of fluorogold (Fluorochrome Inc., Inglewood, $\mathrm{CO}$ ) were placed in the second thoracic segment of the spinal cord 7-14 d prior to death. To enhance the level of $\mathrm{CRH}$ immunostaining, a solution of $80 \mu \mathrm{g}$ cholchicine in $20 \mu \mathrm{l}$ of $0.9 \%$ saline was injected into the lateral cerebral ventricle of 18 rats $3 \mathrm{~d}$ prior to death. To prepare tissue slices for intracellular filling, animals were first anesthetized with $35 \%$ chloral hydrate and then perfused transcardially and sequentially with solutions of $4 \%$ paraformaldehyde in acetate buffer $(\mathrm{pH} 6.5)$ with $0.025 \%$ glutaraldehyde, $4 \%$ paraformaldehyde in borate buffer $(\mathrm{pH} \mathrm{9.5)} \mathrm{with} 0.025 \%$ glutaraldehyde, and $0.1 \mathrm{M}$ PBS. The brains were then removed and cut into $100-\mu \mathrm{m}$-thick frontal sections through the PVH with a Vibratome. Individual sections were placed on subbed slides and kept cold in a pool of phosphate buffer in a humidified chamber until they were placed on the intracellular injection apparatus. In each tissue slice, 5-10 Fast blueor fluorogold-labeled neurons were selectively penetrated and filled intracellularly with pulled $20 \mathrm{M} \Omega$ resistance glass micropipettes. The diffusion of LY, pulsed from the microelectrode tip, was observed with long focal-length water-immersion fluorescence optics. LY diffuses amorphously until the advancing microelectrode penetrates a cell body or process, when the dye becomes confined intracellularly. Finally, after several neurons were filled intracellularly, the tissue sections were processed for immunohistochemistry. A rabbit primary antiserum against rat CRH ( $r 70$, gift of W. Vale), diluted $1 / 2000$, was used for $48 \mathrm{hr}$ at $4^{\circ} \mathrm{C}$, and goat anti-rabbit, rhodamine-conjugated secondary antibodies (Tago Inc., Burlingame, CA), diluted 1/50, were used for $1 \mathrm{hr}$ at room temperature. Tissue sections were then air-dried overnight, cleared in graded ethanols, methyl salicylate, and xylene, and mounted with D.P.X.

Morphometric quantification. To characterize the morphology of identified cell types in the PVH, cleared and mounted tissue sections containing LY-stained neurons were placed on the motor-driven stage of a fluorescence compound microscope coupled to a Joyce-Loebl Magiscan Image Analysis system. Under low magnification, binary outlines were first drawn and superimposed with a lightpen over SITC video images of the cytoarchitectonic boundaries that subdivide and circumscribe the PVH. Then, under higher magnification (I eitz $100 \times$ oil objective with a $10 \times$ phototube), binary outlines of the 5-10 LY-stained neurons in each tissue section were drawn in registration with cytoarchitectonic boundaries and with each other, noting detailed features of axons and dendrites, and counting dendritic spines and axon collaterals. These binary outlines were then combined graphically into multicellular montage drawings, consisting of 50-60 representative neurons that were evenly distributed over the extent of their cytoarchitectonic subdivision. The number of spines, the total dendritic length, and the cross-sectional area of the somata were quantified for all neurons that were reconstructed graphically. Finally, in addition to proprietary software, several commercially available software packages, including Symphony (Lotus Development Co.) and SPSS/PC+ (Microsoft Corp.), were also used for data manipulation and statistical analysis.

\section{Results}

Following the intravenous injection of Fast blue, magnocellular and parvicellular neurosecretory neurons in the PVH appeared to be selectively labeled regrogradely since their axon terminals end in regions that lack a blood-brain barrier (the posterior pituitary and neurohemal zone of the median eminence), and connectional studies indicate that the PVH does not project to any other circumventricular organ (see Rho and Swanson, 1987). On the other hand, injections of fluorogold into the spinal cord led to extensive retrograde labeling of neurons in the dorsal, ventral medial, and lateral parvicellular parts of the nucleus (see Fig. 3, inset). The neuroendocrine population of cells was further divided on 2 grounds. First, magnocellular neurons were localized on topological grounds within the lateral subdivision of the posterior magnocellular part of the nucleus (where the vast majority of neurons are of this class and are vasopressinergic; see Swanson and Sawchenko, 1983). And second, one class of parvicellular neurosecretory neurons was positively identified immunohistochemically with an antiserum to $\mathrm{CRH}$. To enhance CRH immunostaining one group of animals was pretreated with intraventricular colchicine $3 \mathrm{~d}$ prior to death. Both descending and neuroendocrine cell types were filled intracellularly in this material, and the resulting morphology was compared with that from untreated material. To simplify the analysis, one characteristic level through the PVH was chosen for intensive study (Figs. 1-5). This plane of section lies through midrostrocaudal levels of the medial and dorsal parvicellular parts and the lateral subdivision of the posterior magnocellular part of the nucleus.

\section{Neuronal morphology}

From 38 animals, 128 descending neurons and 214 neuroendocrine cells were filled intracellularly with LY and digitally reconstructed with the aid of computer graphics. Forty-four of the neuroendocrine neurons stained intensely in a characteristic punctate manner with anti-CRH (see Fig. $8 H$ ), while 44 others in the posterior magnocellular part of the PVH had distinctive features of magnocellular neurons, including a large soma and characteristic dendrites. Digital outlines of individual neurons were combined graphically into multicellular montage drawings (Figs. 1-5) consisting of 50-60 representative neurons distributed within particular cytoarchitectonic parts of the nucleus and resembling camera lucida drawings of Golgi-stained neurons. However, the morphological features of each neuron in these montage drawings were analyzed separately (see Figs. 6 and 7), and the presumed functional roles of these neurons were characterized on the basis of their location, retrograde labeling, and immunohistochemical staining patterns.

The descending cell population was found to be relatively homogeneous, with many neurons sharing similar morphological features. In sections from animals that had not been treated with colchicine (Fig. 1), they typically gave rise to 3 major dendrites that extend from medium to large cell bodies in a stereotypical tripolar arrangement, and the axon often arises from one of the dendrites. Their dendrites are long and thin and more highly branched than those of neuroendocrine cells. In addition, they tend to course parallel to the long axis of the part of the nucleus they lie within (as viewed in frontal sections). The descending neurons also have a sparse complement of spines (as usually defined at the light microscopic level), which usually have a short, thin stalk with a bulb on the end. Spines may be found on any part of the dendrite, and occasionally on the cell 


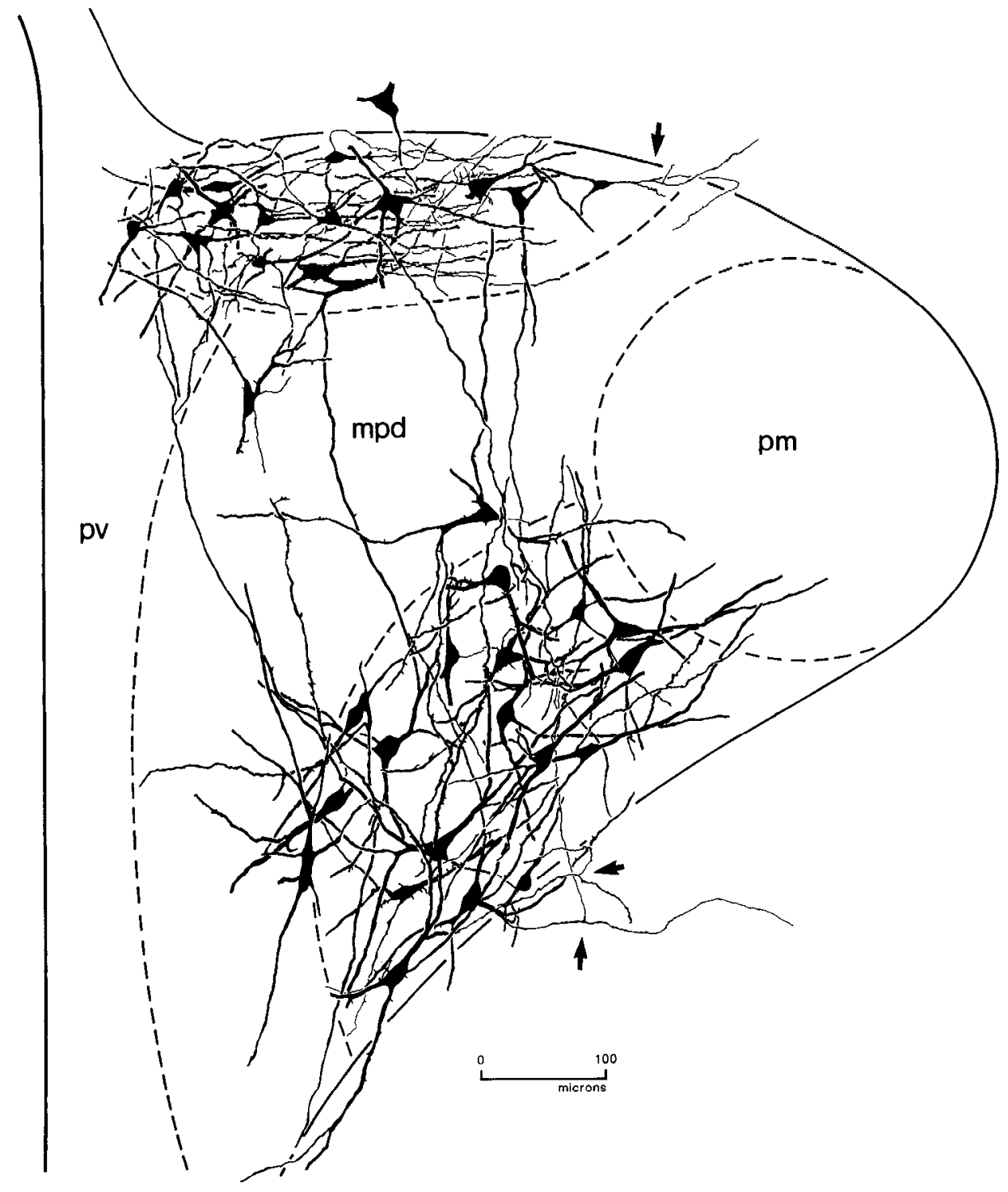

Figure 1. Drawing of the normal morphology of neurons in the dorsal and ventral medial parvicellular parts of the PVH that project to the spinal cord in the adult male rat. In this, and the following 5 figures, LY-filled cells from a number of experiments with tissue sections from approximately the same level have been combined to provide an overview of the total dendritic domain of particular subpopulations. Note that axons indicated by arrowheads give rise to a collateral that reenters the PVH. Compare with Figure 2. Abbreviations: $m d p$, dorsal medial parvicellular; $p m$, posterior magnocellular; $p v$, periventricular. body as well. Although descending neurons in the dorsal and ventral medial parvicellular parts of the PVH are separated by the dorsal medial parvicellular part of the nucleus, the dendrites of some descending neurons span this intervening region and display spines. It should also be pointed out that while the majority of dendrites from descending neurons in the dorsal and ventral medial parvicellular parts of the nucleus stay within their respective cytoarchitectonic borders, a "halo" of secondary dendrites surrounds each region. Thus, some dendrites of descending neurons extend into the medial rim of the lateral posterior magnocellular (vasopressincrgic) part of the nucleus and into the periventricular part of the nucleus, as well as into the dorsal medial parvicellular part.

A distinct axon could be distinguished from dendrites in 22 of the 61 descending neurons examined in normal material. These axons were thin and varicose, and often arose from a primary dendrite, where an axon hillock 5-10 $\mu \mathrm{m}$ long was observed. In a few cases the axon could be traced for several hundred microns, and when this was possible a bifurcation was usually observed. The major branch continued laterally or ventrolaterally toward the lateral hypothalamic area, while the other branch reentered the part of the PVH containing the parent cell body, although its precise site(s) of termination could usually not be determined with certainty (see Fig. 1).

Parvicellular CRH neuroendocrine cells were localized mostly in the dorsal medial parvicellular part of the PVH. These neurons typically have 2 relatively thick primary dendrites that extend from opposite sides of the cell body in a bipolar arrangement and branch once (Fig. 3). In general, the dendrites of these neurons are aligned in such a way that they course more or less parallel to the borders of the dorsal medial parvicellular part of the PVH. When both dendrites wrap around and extend in the same direction to conform to the borders of this part of the $\mathrm{PVH}$, a thin varicose axon typically emerges from the opposite side and extends laterally toward the fornix. The presence of terminal boutons arising from the axon in the zone surrounding the PVH has been described previously (Rho and Swanson, 1987). These cells have several distinct types of spines on their somata and dendrites: large appendage-like extensions are often located on the cell body, long hair-like spines are distributed on the cell body and proximal dendrites, and smaller bulbous-type spines are typical on more distal processes. 
Figure 2. As in Figure 1, neurons that project to the spinal cord are prescnted, except in this figure the animals had been pretreated for $3 \mathrm{~d}$ with colchicine. Abbreviations as in Figure 1.

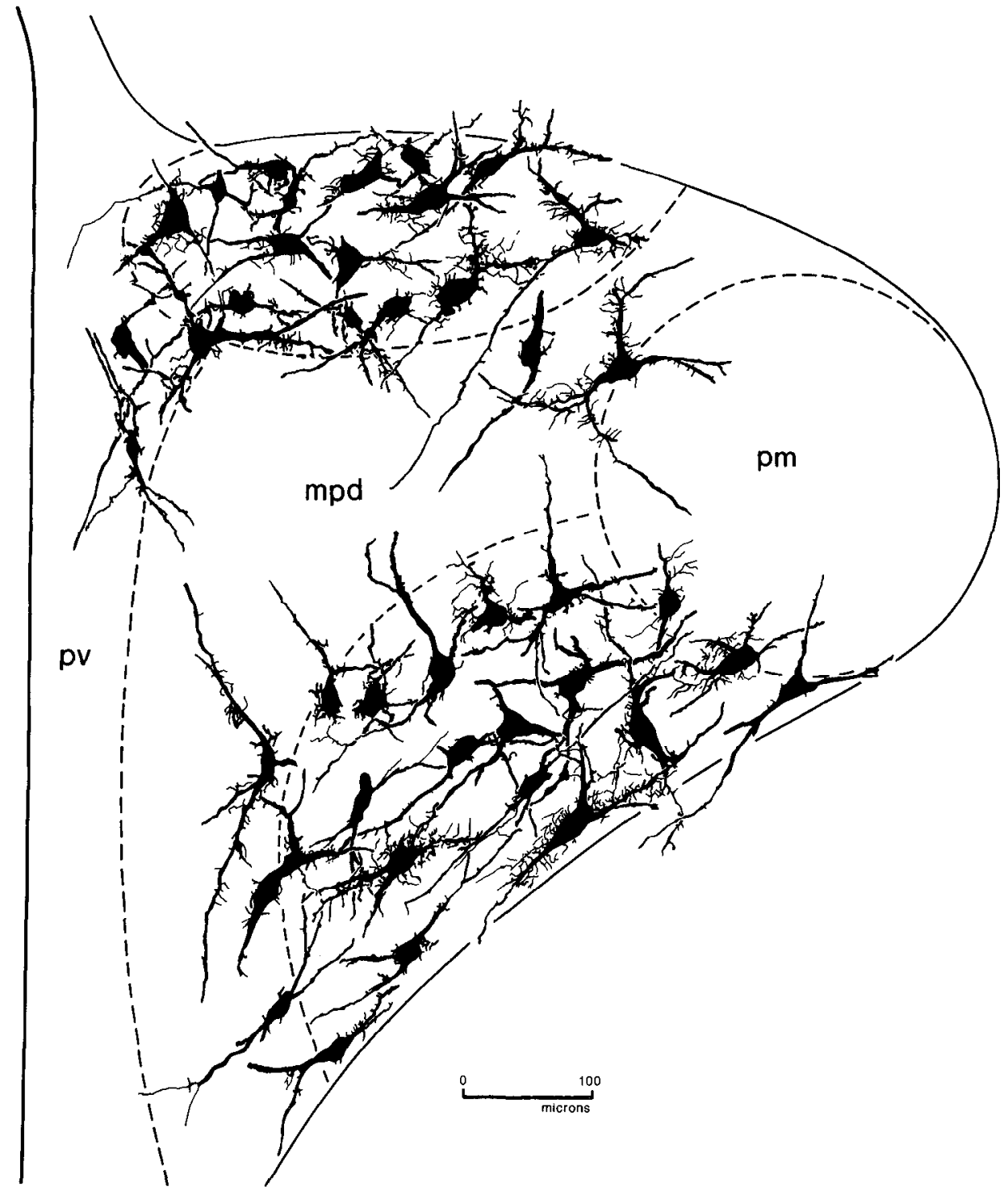

Magnocellular neurosecretory neurons in normal material were distinguished from parvicellular neurosecretory neurons in the present analysis by the size and shape of their somata, which were larger and more rounded, and by thcir location within the lateral area of the posterior magnocellular part of the PVH (Fig. 4). Perhaps due to their dense clustering or to their intimate association with a very high density of capillaries (see Zambrano and de Robertis, 1966), the somata of magnocellular neurons are often highly irregular in shape, with deep invaginations. Surprisingly, however, while their somata were distinctly larger than those of parvicellular neurosecretory neurons, their dendrites and accompanying spines appeared remarkably similar. These dendrites appear to extend throughout the posterior magnocellular part of the PVH and, in many cases, extend medially beyond its cytoarchitectonic boundaries to almost reach the third ventricle. In general, however, the dendrites of these neurons stay within the borders of the posterior magnocellular part of the PVH. The medially directed dendrites tend to course through the medial (oxytocinergic) subdivision of the posterior magnocellular part of the PVH, although they are drawn in the ventral medial parvicellular part of the nucleus in Figure 4 for the sake of convenience. While other large neuroendocrine cells resembling those in the posterior magnocellular region were also sparsely scattered in other parts of the PVH, they were not included in the sample of magnocellular neurosecretory neurons used for quantitative analysis (below).

\section{Quantitative comparisons}

In untreated animals, the mean cross-sectional area of descending somata is similar to that for the total neuroendocrine population. However, because the dendrites of descending neurons are more highly branched, their total length is significantly greater than that for the neuroendocrine cells. If the descending population is differentiated into dorsal and ventral groups, the mcan somal area and the total dendritic length of neurons in the ventral medial group is larger than that for neurons in the dorsal group. Similarly, if the total neuroendocrine population (Fig. 4) is separated into parvicellular and magnocellular groups, the mean somal area of magnocellular neurons is larger. However, despite this size difference, the total dendritic length and the spine density of the 2 neuroendocrine groups were not significantly different. 


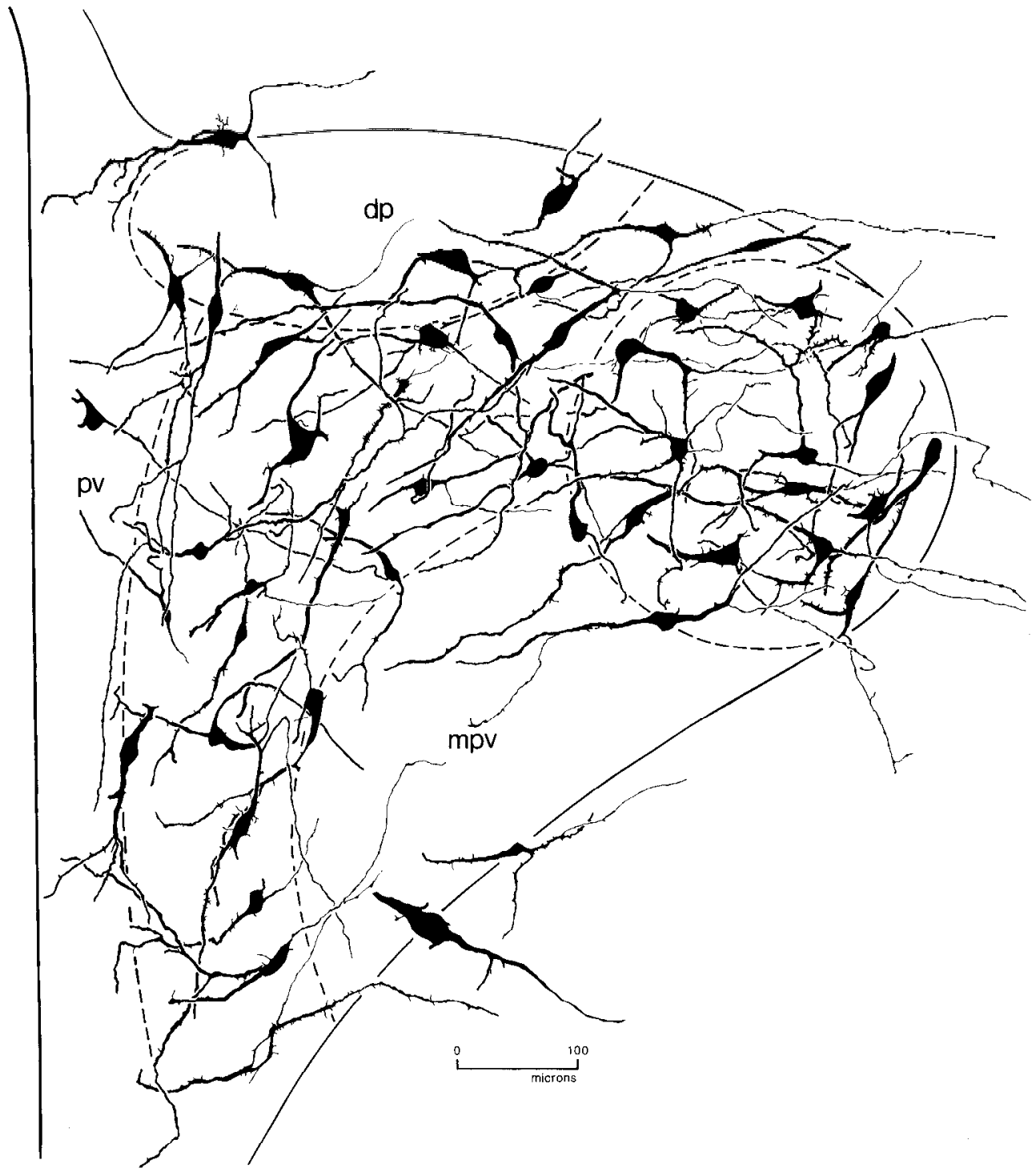

Figure 3. Representative sample of LY-filled fluorescent cells that had been retrogradely labeled with Fast blue after the tracer was injected intravenously. Both magnocellular and parvicellular neurosecretory neurons are illustrated, and were taken from brain tissue that had not been pretreated with colchicine or subjected to immunohistochemical staining (compare with Figs. 4 and 5). Abbreviations: $d p$, dorsal parvicellular; $m p v$, ventral medial parvicellular; $p v$, periventricular.
After treatment with colchicine for $72 \mathrm{hr}$, the mean somal area of both the descending (Fig. 2) and the neuroendocrine (Fig. 5) populations increased significantly (32\%), although the increase was larger in the descending group (52\%) than in the neuroendocrine group (21\%). Even though the dorsal descending neurons were distinguishable from the ventral descending neurons in both mean somal area and total dendritic length in untreated animals, after treatment with colchicine, both groups demonstrated similar mean somal areas and total dendritic lengths. After treatment with colchicine, the mean somal area of both the parvicellular and magnocellular neuroendocrine groups also increased significantly; here, the magnocellular neurons showed an average increase of $49 \%$, whereas the parvicellular neurons showed a $39 \%$ increase in mean somal area. The mean total dendritic length of parvicellular neurons was indistinguishable from that for magnocellular neurons in untreated animals, and after colchicine treatment, they were both reduced to a similar extent.

Treatment with colchicine also appeared to influence the number and types of appendages on descending and neuroendocrine cells in quite selective ways (Figs. 6-8). In untreated animals, descending neurons have a sparse distribution of small bulbous spines; however, after treatment with colchicine, numerous hair-like spines (more typical of neuroendocrine cells) became apparent on their somata and proximal dendrites. The density of appendages, as measured by taking the ratio of the number of appendages to the total dendritic length, also increased dramatically, from an average density of 1.7 to 12.9 spines $/ 100 \mu \mathrm{m}$. The density of spines on dorsal descending neurons was not significantly different from that for ventral medial descending neurons in untreated animals, and, after colchicine treatment, both types were affected to a similar extent. The density of spines on neuroendocrine cells was also changed by colchicine treatment, increasing from an average of 8.7 to 19.3 spines $/ 100 \mu \mathrm{m}$. Before treatment with colchicine, the average spine densities of magnocellular and parvicellular neurosecretory neurons were similar, and after colchicine, the density of spines increased somewhat more for the magnocellular subpopulation.

\section{Discussion}

The technique used here has allowed us to characterize the total dendritic field of large populations of specific cell types within a cytoarchitectonically defined nucleus, as well as to provide 
Figure 4. As in Figure 3, drawings of representative neurosecretory neurons in the PVH are illustrated, except that here the animals were pretreated with colchicine. Abbreviations as in Figure 3.
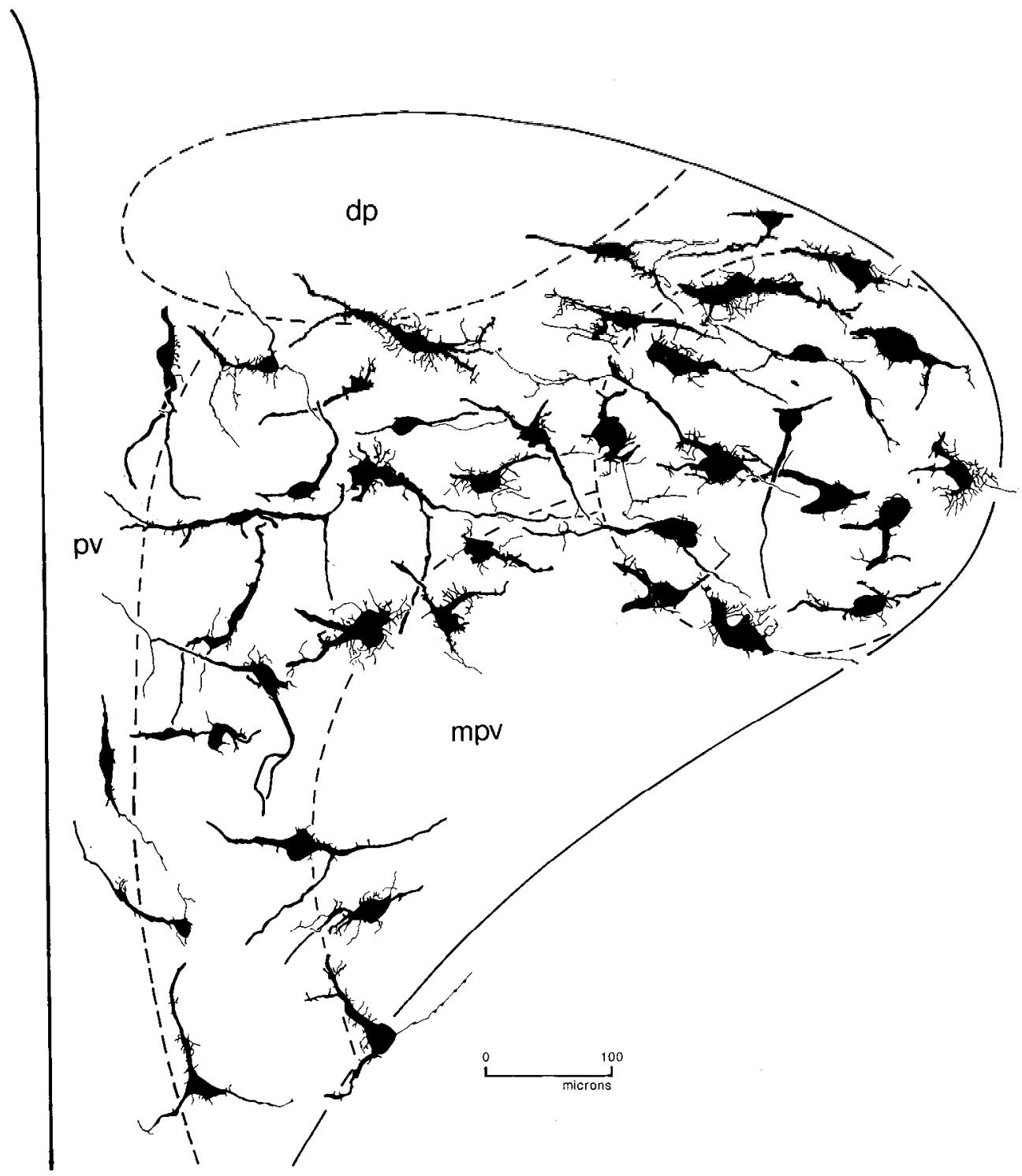

quantitative information about the morphological features of individual cell types within these populations. There are 3 major advantages to the approach used here. First, cells that have been retrogradely labeled from a specific terminal field can be filled with LY under visual inspection in a single tissue section, which can then be subjected to immunostaining for additional information about filled cells. Second, the method is convenient for gathering information about large populations, since many cells can be filled in each tissue section. And third, quantitative morphological comparisons can be made relatively easily between control and experimental conditions for a particular cell type.

The major disadvantage of the method is that dendrites and axons may be cut off because the filled cells lie within a 100 $\mu \mathrm{m}$-thick section. For a particular plane of section, this problem can be approached in a statistical way, since many cells can be filled and many apparently intact dendrites can be observed. However, a more complete characterization of a population of cells would require its analysis in the 3 standard planes of section. This is particularly relevant when attempting to determine the significance of morphological differences between topographically separate populations of cells, such as the dorsal and ventral medial descending groups studied here. In the end, however, the method described here cannot provide definitive evidence about the total extent of dendrites and the axon of individual neurons; only estimates based on populations can be provided. The full morphology of individual cells can be provided only by the Golgi method or by filling cells in intact animals and subsequently reconstructing them in serial sections. With these approaches, however, it is difficult to characterize cells immunohistochemically or to sample large numbers of cells.

It is well established that most neurons in the PVII with descending projections to the brain stem and spinal cord are found in the dorsal, ventral medial, and lateral parvicellular parts of the nucleus (Hosoya and Matsushita, 1979; Swanson and Kuypers, 1980). Van Den Pol (1982) has illustrated the appearance of Golgi-impregnated cells in the lateral parvicellular part of the nucleus, and while it cannot be stated with certainty which of these cells gives rise to descending projections, the morphology of several of them is quite similar to those we have filled in the dorsal and ventral medial parvicellular parts of the nucleus. Our analysis of retrogradely labeled 


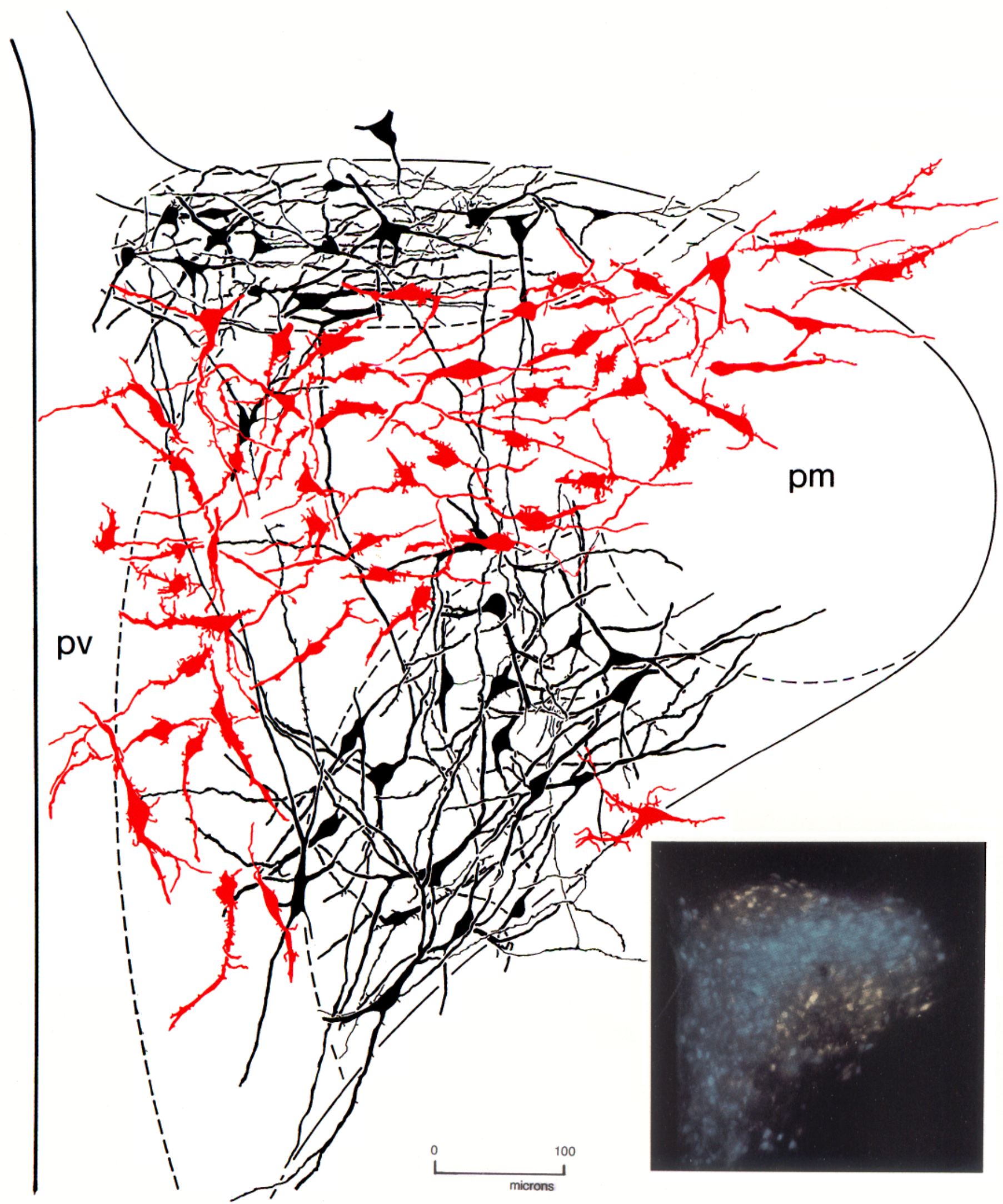

Figure 5. This drawing illustrates the morphology of CRH-immunostained neurons (red) in the dorsal medial parvicellular part of the PVH that had been retrogradely labeled from the median eminence and several days later treated with colchicine. For comparison, neurons that project to the spinal cord are drawn in black. Inset, Photomicrograph showing the appearance of retrograde labeling in the PVH following a fluorogold injection in the spinal cord and an intravenous injection of Fast blue. $\times 50$. 

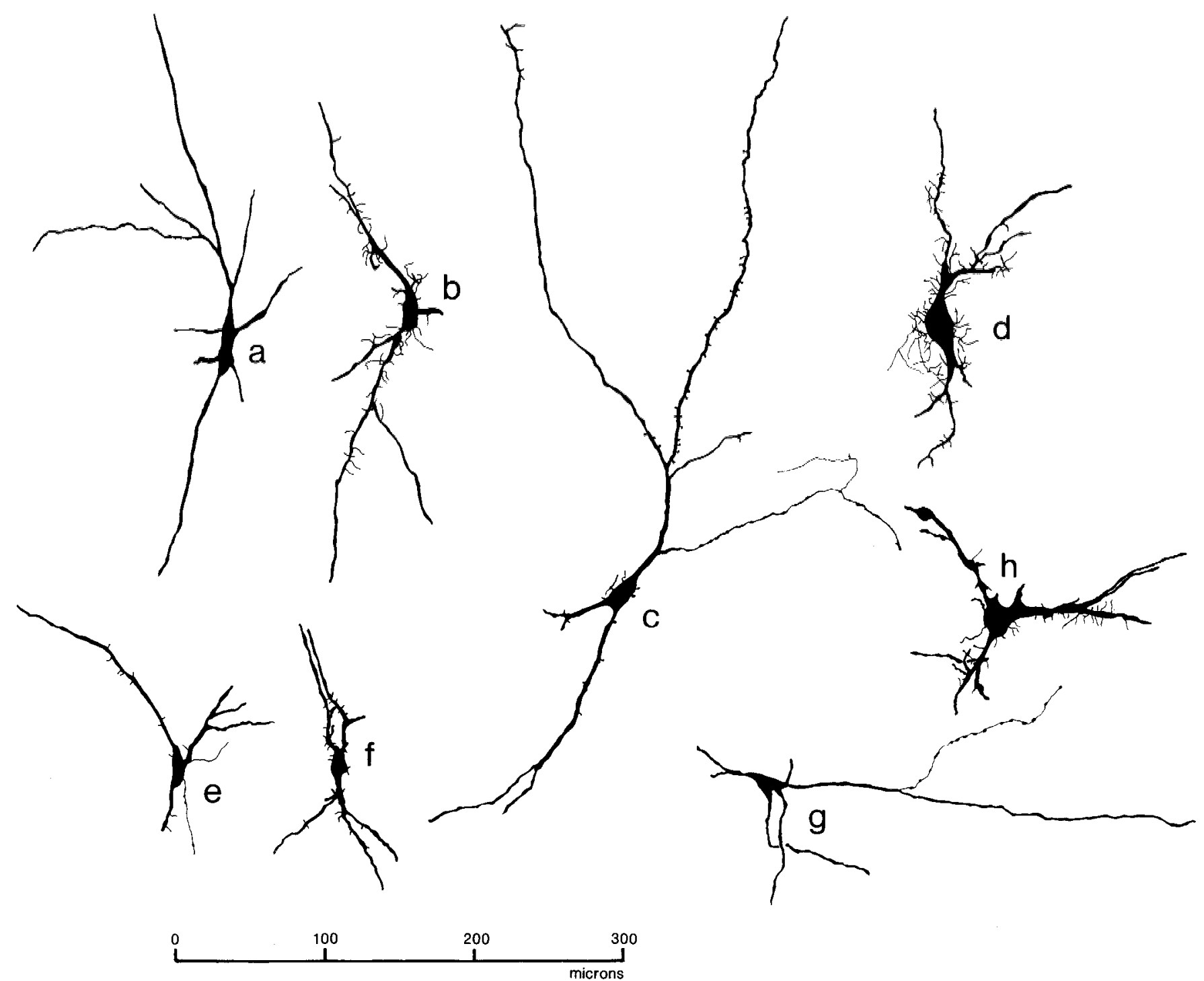

Figure 6. These drawings show in more detail the morphology of individual neurons in the PVH that project to the spinal cord. $a$ and $c$, Cells in the ventral medial parvicellular part of the nucleus; no colchicine. $b$ and $d$. Cells in the ventral medial parvicellular part; colchicine pretreatment. $e$ and $g$, Dorsal parvicellular part; no colchicine. $f$ and $h$. Dorsal parvicellular part; colchicine pretreatment.

neurons in these 2 regions indicates that a majority of their dendrites lie within the cytoarchitectonically defined borders of these regions. However, it is also clear that their secondary dendrites extend to form a halo that is on the order of 20-50 $\mu \mathrm{m}$ wide around each region and that the dendrites of some neurons in one region extend through the area (the dorsal medial parvicellular part) between them to reach the other region. One such neuron in what is probably the dorsal parvicellular part of the nucleus was illustrated by Van Den Pol (1982, his figure $4 \mathrm{~B}$ ), although he identified the cell as "magnocellular," apparently on the basis of its size alone.

These results indicate that a majority, but certainly not all, of the neural inputs to descending neurons in the dorsal and ventral medial groups form synapses within the cytoarchitectonic boundaries of these groups and within the zone immediately surrounding them. A similar arrangement was found for parvicellular CRH neuroendocrine cells in the dorsal medial parvicellular part of the PVH: most of their dendrites stay within (and course parallel to the long axis of) this region, although some clearly extend into adjacent areas.
We did not examine the dendritic fields of magnocellular neuroendocrine neurons in the lateral posterior magnocellular part of the PVH in as much detail as the populations of descending and CRH neuroendocrine cells. However, it is clear that some dendrites of magnocellular neurosecretory neurons extend beyond the limits of the lateral posterior magnocellular part of the PVH, particularly medially, where many of them course in or near the medial area (predominantly oxytocinergic) of the posterior magnocellular part of the nucleus toward the third ventricle. In addition, many dendrites curve to stay within the lateral borders of the cell group. This general pattern confirms earlier work in the rat PVH hy Armstrong et al. (1980) and Van Den Pol (1982), and the evidence suggests that the dendrites of magnocellular neurons also stay largely within the limits of the supraoptic nucleus (Leontovich 1969/1970; Armstrong et al., 1982; Dyball and Kemplay, 1982; Randle et al., 1986).

It should also be pointed out that the dendrites of neurons in the relatively cell-sparse zone surrounding the PVH tend to run parallel to the border of the nucleus, which they rarely cross 


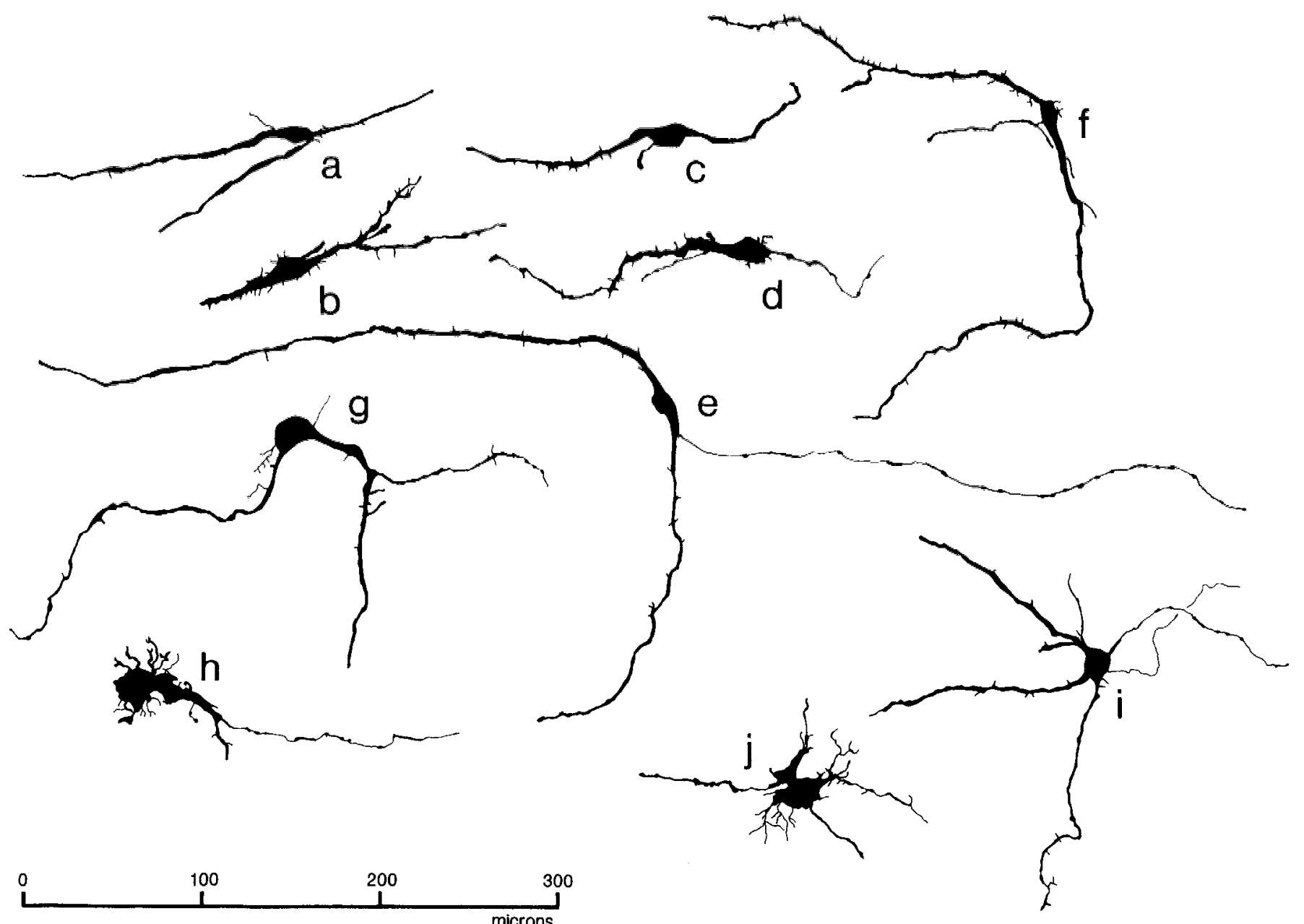

Figure 7. Drawings of individual neuroendocrine neurons in the PVH. $a, c$, and $e$, Cells in the dorsal medial parvicellular part of the nucleus; no colchicine. $b$ and $d$, CRH-immunostained neurons in the dorsal medial parvicellular part of the nucleus; colchicine pretreatment. $f$, CRH-immunonegative cells in the dorsal medial parvicellular part of the PVH; colchicine. $g$ and $i$, Large neurons in the lateral subdivision of the posterior magnocellular part of the $\mathrm{PVH}$; no colchicine. $h$ and $j$, Magnocellular neurosecretory neurons in the same region as in $g$ and $i$; colchicine pretreatment. All of the neurons shown here were retrogradely labeled following intravenous injections of Fast blue.

(see figure 2 in Van Den Pol, 1982). The view that emerges from the evidence taken as a whole is that the dendrites of neurons in the PVH show a strong tendency to stay within the nucleus itself, while the distal parts of dendrites from cells within a specific part of the nucleus form a relatively thin halo in adjacent regions of the nucleus. In addition, the dendrites of some descending and magnoccllular ncurosccretory neurons extend well into the medial parvicellular part of the nucleus, and even into its periventricular zone.

The method used here is particularly suited for characterizing the total dendritic field of a defined population of neurons, an important consideration when mapping the distribution of neural inputs. Earlier work along these lines had to rely solely upon cytoarchitectonic boundaries, and the generalization that emerged was that most projections end within specific parts of the PVH (see Sawchenko and Swanson, 1982a; Swanson et al., 1986, for reviews). This approach does not take into account the orientation and extent of dendrites, or the fact that each part of the PVH harbors a mixture of cell types, even though one class usually predominates. For example, at least $88 \%$ of the neurons in the dorsal parvicellular part of the PVH project to the spinal cord (Sawchenko and Swanson, 1981), and the vast majority of neurons in the posterior magnocellular and dorsal medial parvicellular parts of the nucleus are neurosecretory (see Sherlock et al., 1975; Armstrong et al., 1980; Swanson et al., 1987). However, a complete understanding of the synaptology of PVH circuitry will require ultrastructural evidence that includes a knowledge of the origin and neurotransmitter content of the presynaptic element, as well as the projections and neurotransmitter content of the postsynaptic element. Furthermore, it will be important to determine the extent to which individual axons of known origin innervate one or more cell types within the $\mathrm{PVH}$, as this has a direct bearing on mechanisms underlying the coordination of responses mediated by the nucleus. The results of the present study support the view that a projection ending heavily and selectively within one of the parts of the PVH examined here preferentially innervates neurons in that part of the PVH. However, no part of the PVH contains a homogenous population of neurons, and similarly the dendrites of neurons in a particular part of the nucleus are not strictly confined to that part.

The morphology of individual cell types in the PVH has only been clarified in the last several years. Early workers commented on the difficulty of impregnating what we now know are mag- 

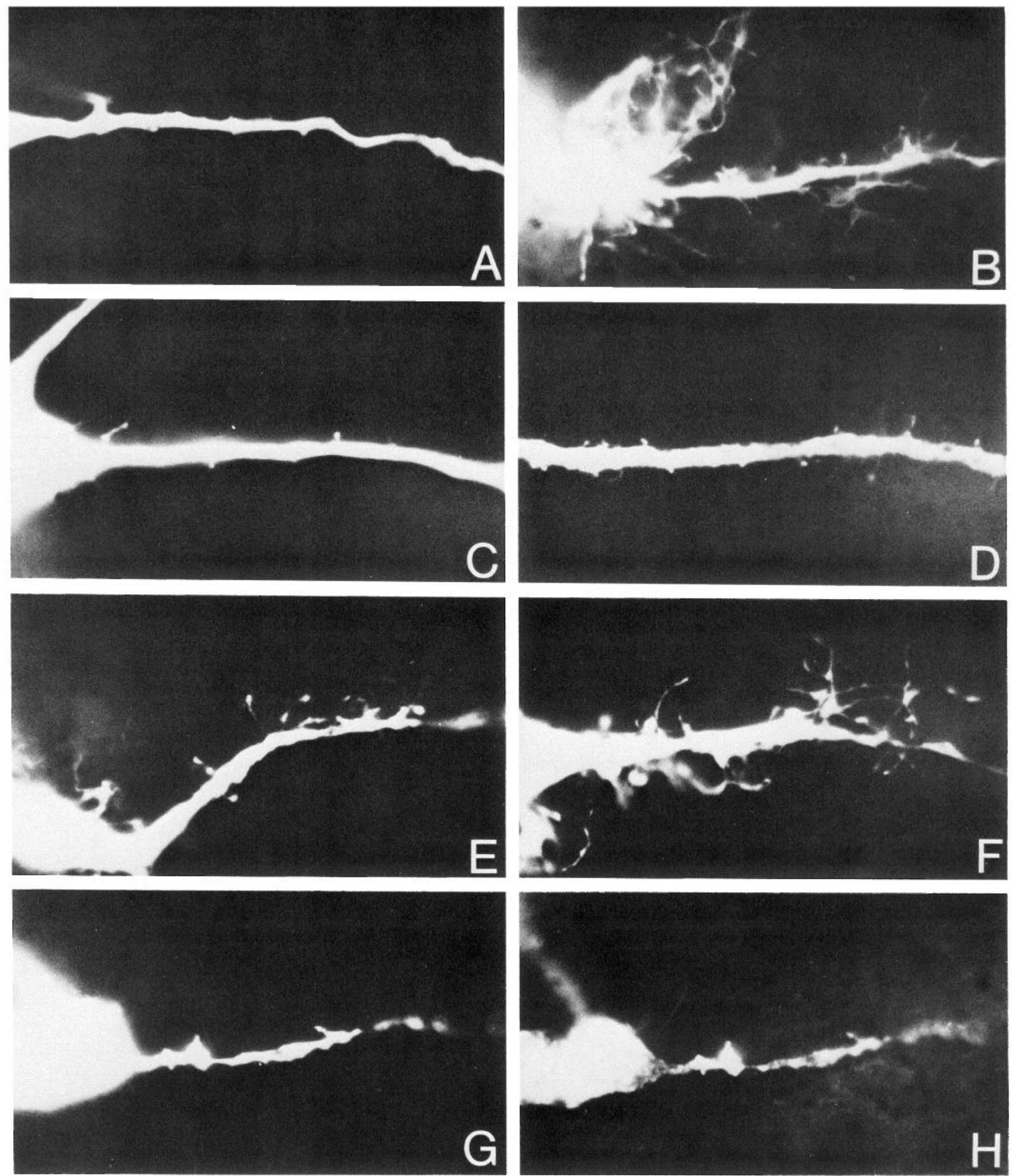

Figure 8. Photomicrographs to illustrate the appearance of dendritic appendages on various cell types in the VPH. $A$ and $B$, Untreated $(A)$ and colchicine-treated $(B)$ descending neurons in the dorsal parvicellular part. $C$ and $D$, Untreated $(C)$ and colchicine-treated $(D)$ parvicellular neurosecretory neurons in the dorsal medial parvicellular part. $E$ and $F$, Untreated $(E)$ and colchicine-treated $(F)$ magnocellular neurosecretory neurons in the lateral posterior magnocellular part. $G$ and $H$, LY-filled $(G)$ and CRH-immunostained $(H)$ parvicellular neurosecretory neurons in the dorsal medial parvicellular part. All micrographs $\times 1250$. 
noccllular ncurosecretory cells (Cajal, 1894; Szentágothai et al., 1968), although several large neurons with 2 or 3 simple dendrites in the supraoptic (Gurdjian, 1927; Krieg, 19.32) and PVH (Krieg, 1932) of the rat were illustrated rather early on, and Lefranc and Courrier (1966) demonstrated similar neurons with sparse dendritic spines in the kitten and neonatal guinea pig. The first detailed study of this problem was published by Leonlovich (1969/1970), who showed that most neurons in the puppy supraoptic nucleus are bipolar with short "sticklike" spines on the dendrites and somata. The dendrites are simple and may branch once, and they generally stay within the borders of the nucleus. Similar neurons were observed in the PVH, although their dendrites were said to ramify somewhat more broadly. This general description of neurons in the supraoptic nucleus has since been confirmed with the Golgi method in the adult rat (Ifft and McCarthy, 1974; Armstrong et al., 1982; Dyball and Kemplay, 1982), monkey (LuQui and Fox, 1976), and rabbit (Felten and Cashner, 1979), and with the intracellular LY filling of neurons in rat hypothalamic slices (Andrew et al., 1981) or explants (Randle et al., 1986).

Large cells in the PVH were also described in Golgi studies of the mouse (Barry, 1975), and Van Den Pol (1982) showed that such neurons in the rat display somatic and dendritic spines. This description is similar to that for LY-filled neurons that project to the posterior pituitary in the cat (Reaves and Hayward, 1981) and to vasopressin- and oxytocin-stained neurons in the rat (Sofroniew and Glasmann, 1981; Kayser et al., 1982), although the latter authors did not comment on the presence of spines.

Ultrastructural studies in the mouse and rat supraoptic nucleus have confirmed the existence of synapses on somatic and dendritic spines, as well as on the soma itself and on the dendritic shafts (Polenov and Senchik, 1966; Eneström, 1967; Rechardt, 1969; Léránth et al., 1971, 1975; Ifft and McCarthy, 1974). In the rat, Léránth et al. (1975) have even estimated that, on average, each magnocellular neurosecretory neuron receives on the order of 600 synapses, with about 500 equally distributed on dendritic shafts and spines, and the rest on the soma and axon. In the rat $\mathrm{PVH}$, synapses have also been reported on the soma and dendrites, on somatic and dendritic spines, and on the axon of magnocellular neurosecretory neurons (Van Den Pol, 1982; Piekut, 1983; Silverman et al., 1983). Thus, our rather limited examination of magnocellular neurosecretory neurons is fully consistent with the substantial earlier literature on such neurons in the PVH and supraoptic nucleus in a variety of mammalian species.

The issue of the extent to which the axon of magnocellular neurosecretory neurons gives rise to collaterals is somewhat controversial. There appears to be general agreement (see Eneström, 1967; Leontovich, 1969/1970; Mason et al., 1984; Hatton et al., 1985; Randle et al., 1986) that collaterals do not arise, or are very infrequent, within the PVH and supraoptic nuclei themselves, which is in agreement with our results. On the other hand, at least some terminal boutons (Randle et al., 1986) or longer collaterals (Mason et al., 1984; Hatton et al., 1985) appear to arisc outside the nuclei, in the lateral hypothalamic area, before the parent axon enters the pituitary stalk. We observed that it was sometimes difficult to identify unequivocally the axon of neurosecretory cells in our material, particularly when it arose from a primary dendrite. It has been noted that the axon hillock of magnocellular neurosecretory neurons can be quite large (e.g., Carrato Ibáñez, 1952), and often contains rough endoplasmic
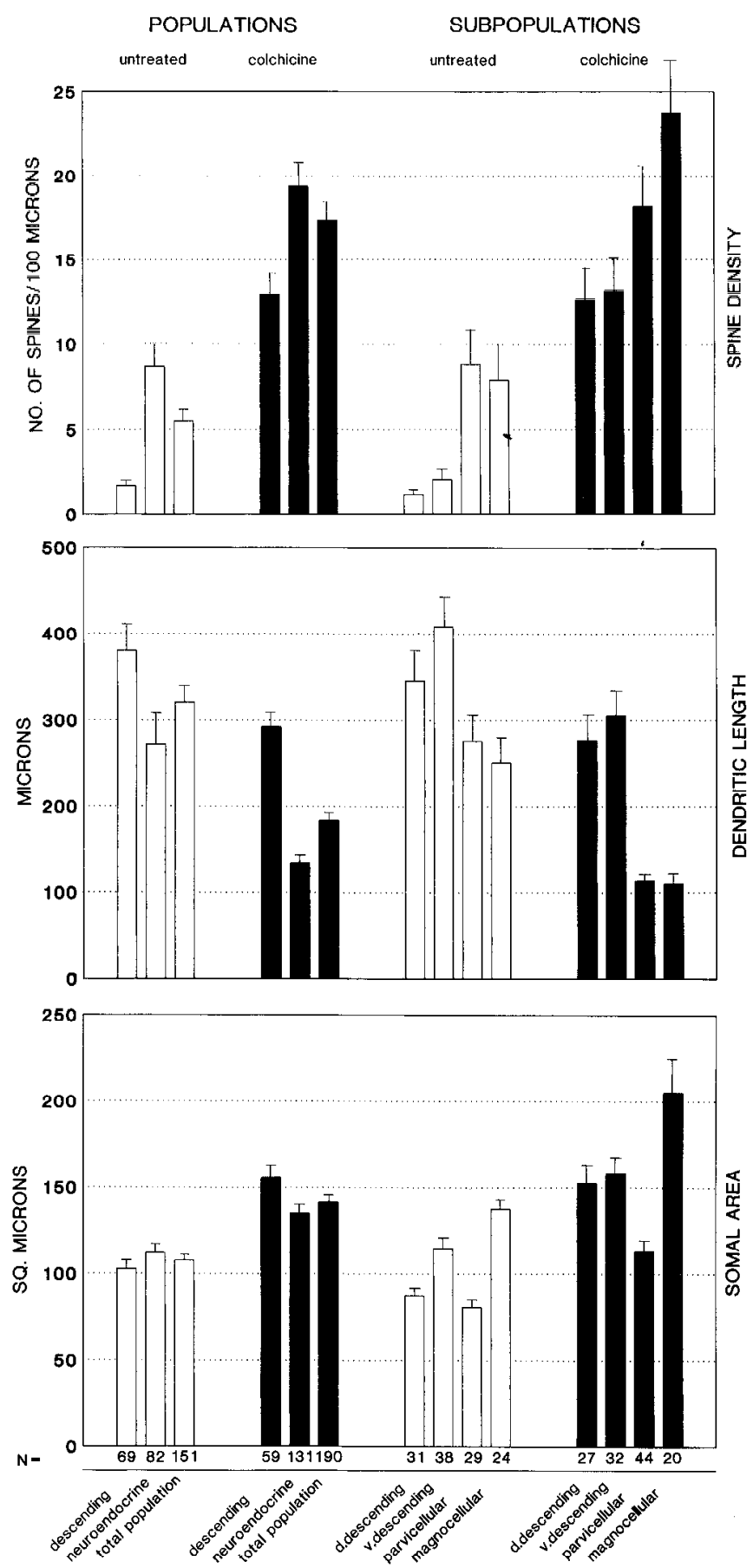

Figure 9. Quantitative analyses of the effects of colchicine on neuron morphology in the PVII. With computer graphics, the mean ( $\perp$ SEM) somal cross-sectional area, total dendritic length (within the $100-\mu \mathrm{m}$ thick tissue section), and spine density of individual cells were determined, and comparisons between different populations and subpopulations were made. The total neuroendocrine population (left) included all retrogradely labeled neurons in the PVH following an intravenous injection of Fast blue; parvicellular (right) refers just to cells in the dorsal medial parvicellular part, and magnocellular refers just to cells in the lateral posterior magnocellular part of the PVH. The numbers $(N)$ of cells in each group are listed below each column.

reticulum and ribosomes (Eneström, 1967). Nevertheless, the anatomical evidence as a whole does not support the existence of recurrent collaterals for magnocellular neurosecretory neurons, and it has been suggested that electrophysiological evi- 
dence for recurrent inhibition may have been misinterpreted, since these cells often show a 30-100 msec silent period following the generation of an action potential (see Leng, 1981).

Much less is known about the morphology of parvicellular

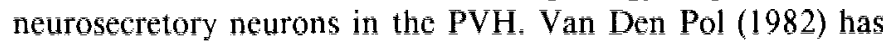
described Golgi-impregnated neuronons siminilar in appearance tó those illustrated here, although he could not further classify them. This is a problem because the PVH contains neurons projecting to the median eminence that contain CRH (Bloom et al., 1982; Antoni ct al., 1983), TRH (Aizawa and Grecr, 1981; Brownstein et al., 1982), somatostatin (Sawchenko and Swanson, 1982b; Ishikawa et al., 1987), GRH (Sawchenko et al., 1985; Bruhn et al., 1987), and dopamine (Swanson et al., 1981; Kawano and Daikoku, 1987). Liposits et al. (1983, 1985) approached this problem using immunohistochemical staining at the ultrastructural level and demonstrated that CRH cells in the dorsal medial parvicellular part of the PVH display somatic and dendritic spines and that synapses are formed with these appendages, as well as directly on the somatic membrane. Léránth et al. (1983) have also presented ultrastructural evidence that as the axons of magnocellular neurosecretory cells pass through the dorsal medial parvicellular part of the PVH, they may form synapses with the somata of CRH neurons. Our results confirm the presence of relatively infrequent somatic and dendritic spines on parvicellular neurosecretory CRH neurons. They also indicate not only that the cells are smaller than magnocellular neurosecretory cells, but also that they tend to have a more elaborate dendritic tree, although the density of spines in the 2 classes of neurons is similar. It has not been possible to follow the axons of these CRH neurons for any great distance in our $100-\mu \mathrm{m}$ thick sections. However, as with magnocellular neurosecretory neurons, axon collaterals and terminal boutons appear to be very infrequent within the PVH itself, although they have been detected within the zone immediately surrounding the nucleus (Rho and Swanson, 1987). The experimental approach used in the present work to identify parvicellular neurosecretory $\mathrm{CRH}$ cells is important because some neurons in the PVH that express CRH are magnocellular neurosecretory neurons, which also express oxytocin (Sawchenko et al., 1984) or are neurons with descending projections (Swanson et al., 1986).

This is the first report on the detailed morphology of descending neurons in the PVH, although Golgi-impregnated cells with a similar morphology and location were described by Van Den Pol (1982). Interestingly, these cells have longer dendrites, and considerably fewer spines, than neurosecretory cells in the PVH, although their somata are, on the average, intermediate in size between the parvicellular and magnocellular neurosecretory cells. It is worth pointing out that neurons in the ventral descending group tend to be larger than those in the dorsal group, when viewed in the frontal plane. This is of interest in view of evidence that neurons in the ventral group project densely to both the dorsal vagal complex and the spinal cord, whereas neurons in the dorsal group project heavily to the spinal cord but much less heavily to the dorsal medulla (Swanson and Kuypers, 1980). However, an analysis of these two cell groups in all 3 planes of scction will be necessary to determine whether the differences observed are due to changes in cell orientation or morphology.

Finally, the present results indicate that colchicine treatment leads to the swelling of neuronal somata, the swelling and shortening of dendrites, and an increase in the number and length of somatic and dendritic appendages; and that the extent of these changes depends upon cell type. The dendritic and somatic ap- pendages vary widely in morphology, from large, complex structures, to typical bulbous spines, to thin, hair-like processes. While many of these processes may be dendritic or somatic spines, it is possible that at least some of them are cilia. These structures, which may be $0.2-0.3 \mu \mathrm{m}$ in diameter and up to 5 $\mu \mathrm{m}$ long, were first described in magnocellular neurosecretory cells of the goldfish (Palay, 1961), and subsequently in neonatal (Lafarga et al., 1980), mature (Eneström, 1967), and aged (Suarez et al., 1985 ) magnocellular neurosecretory cells of mammals. It has been known for some time that colchicine and related drugs increase the number of cilia on a variety of cell types, including fibroblasts (Stubblefield and Brinkley, 1966) and brain glial cells (Milhaud and Pappas, 1968). Interestingly, it has been reported that increased activity of the magnocellular neurosecretory system stimulates proliferation of pituicyles in the posterior lobe (Selye and Hall, 1943), and that this is accompanied by an increased number of cilia, which is accentuated by the administration of microtubule poisons such as colchicine (see Dustin et al., 1979). Although it is not clear whether these changes are due to the well-known disruption of microtubules by colchicine, the results suggest that the drug may influence an intrinsic mechanism that regulates the number, morphology, and location of somatic and dendritic appendages. There is evidence to suggest that during early stages of development, many neurons display far more spines, of varying shapes and sizes, than in the fully differentiated state (see Morest, 1969).

\section{References}

Aizawa, T., and M. A. Greer (1981) Delineation of the hypothalamic area controlling thyrotropin secretion in the rat. Endocrinology 109: 1731-1737.

Andrew, R. D., B. A. MacVicar, F. E. Dudek, and G. I. Hatton (1981) Dye transfer through gap junctions between neuroendocrine cells of rat hypothalamus. Science $211: 1187-1189$.

Antoni, F. A., M. Palkovits, G. B. Makara, E. A. Linton, P. J. Lowry, and J. Z. Kiss (1983) Immunoreactive corticotropin-releasing hormone in the hypothalamoinfundibular tract. Neuroendocrinology 36 : $415-423$.

Armstrong, W. E., S. Warach, G. I. Hatton, and T. H. McNeill (1980) Subnuclei in the rat hypothalamic paraventricular nucleus: A cytoarchitectural, horseradish peroxidase and immunocytochemical analysis. Neuroscience 5: 1931-1958.

Armstrong, W. E., J. Schöler, and T. H. McNeill (1982) Immunocytochemical, Golgi and electron microscopic characterization of putative dendrites in the ventral glial lamina of the rat supraoptic nucleus. Neuroscience 7: 679-694.

Barry, J. (1975) Essai de classification, en technique de Golgi, des diverses catégories de neurones du noyau paraventriculaire chez la Souris. C.R. Seances Soc. Biol. 169: 978-980.

Bloom, F. E., E. L. F. Battenberg, J. Rivier, and W. Vale (1982) Corticotropin releasing factor (CRF): Immunoreactive neurones and fibers in rat hypothalamus. Regulat. Peptides 4: 43-48.

Brownstein, M. J., R. L. Eskay, and M. Palkovits (1982) Thyrotropin releasing hormone in the median eminence is in processes of paraventricular nucleus neurons. Neuropeptides 2: 197-201.

Bruhn, T. O., E. L. P. Anthony, P. Wu, and I. M. D. Jackson (1987) GRF immunoreactive neurons in the paraventricular nucleus of the rat: An immunohistochemical study with monoclonal and polyclonal antibodies. Brain Res. 424: 290-298.

Carrato Ibáñez, A. (1952) Aportaciones a la citologia del sistema hipotalamo-hipofisario. Trab. Inst. Cajal Invest. Biol. 44: 159-210.

Dustin, P., A. Anjo, and J. Flament-Durand (1979) Centriologenesis and ciliogenesis in rat pituicytes. Biol. Cellulaire 34: 227-236.

Dyball, R. E., and S. K. Kemplay (1982) Dendritic trees of neurones in the rat supraoptic nucleus. Neuroscience $7: 223-230$.

Eneström, S. (1967) Nucleus supraopticus. A morphological and experimental study in the rat. Acta Pathol. Microbiol. Scand. 186: 1101. 
Felten, D. L., and K. A. Cashner (1979) Cytoarchitecture of the supraoptic nucleus. Neuroendocrinology 29: 221-230.

Gurdjian, E. S. (1927) The diencephalon of the albino rat. J. Comp. Neurol. 43: 1-114.

Hatton, G. I., P. Cobbett, and A. K. Salm (1985) Extranuclear axon collaterals of paraventricular neurons in the rat hypothalamus: Intracellular staining, immunocytochemistry and electrophysiology. Brain Res. Büll, 14: 123=132,

$\bar{I} \bar{I}$ osoya, $\bar{Y}_{;}$, and $\bar{M}_{;}$. Matsushita (1979) Identification and distribution of the spinal and hypophysial projection neurons in the paraventricular nucleus of the rat. A light and electron microscopic study with the horseradish peroxidase method. Exp. Brain Res. 35: 315=331.

Ifft, J. D., and L. MeCarthy (1974) Somatic spines in the supraoptic nucleus of the rat hypothalamus. Cell Tissue Res. 148: 203-211.

Ishikawa, K., Y. Taniguchi, K. Kurosumi, M. Suzuki, and M. Shinoda (1987) Immunohistochemical identification of somatostatin-containing neurons projecting to the median eminence of the rat. Endocrinulogy 121:94-97.

Kawano, H., and S. Daikoku (1987) Functional topography of the rat hypothalamic dopamine neuron systems: Retrograde tracing and immunohistochemical study. J. Comp. Neurol. 265: 242-253.

Kayser, B. E. J., M. Mühlethaler, and J. J. Dreifuss (1982) Paraventricular neurones in the rat hypothalamic slice: Lucifer yellow injection and immunocytochemical identification. Experientia 38: $391-$ 393.

Krieg, W. J. S. (1932) The hypothalamus of the alhino rat. J. Comp Neurol. 55: 19-89.

Lafarga, M., J.-P. Hervás, D. Crespo, and J. Villegas (1980) Ciliated neurons in supraoptic nucleus of rat hypothalamus during neonatal period. Anat. Embryol. 160: 29-38.

Lefranc, M. G., and M. R. Courrier (1966) Étude neurohistologique des noyaux supraoptique et paraventriculaire che le Cobaye et le Chat par la technique de triple imprégnation de Golgi. C.R. Acad. Sci. Paris 263: 976-978.

Leng, $G$. (1981) The effects of neural stalk stimulation upon firing pattern in rat supraoptic neurones. Exp. Brain Res. 41: 135-145.

Leontovich, T. A. (1969/1970) The neurons of the magnocellular neurosecretory nuclei of the dog's hypothalamus. A Golgi study. J. Hirnforsch. 11: 499-517.

Léránth, C., L. Zaborszky, G. Makara, and M. Palkovits (1971) Degeneration von Synapsen im Nucleus supraopticus nach Unterbrechung der afferenten Systeme des Hypothalamus. 66. Vers Anat. Ges. (Zagreb) Anat. Anz. Erg. N. Bd. 130:587-593.

Léránth, C., L. Záborszky, J. Marton, and M. Palkovits (1975) Quantitative studies on the supraoptic nucleus in the rat. I. Synaptic organization. Exp. Brain Res. 22: 509-523.

Léránth, C., F. A. Antoni, and M. Palkovits (1983) Ultrastructural demonstration of ovine CRF-like immunoreactivity (oCRF-LI) in the rat hypothalamus: Processes of magnocellular neurons establish membrane specializations with parvocellular neurons containing oCRFLI. Regulat. Peptides 6: 179-188.

Liposits, Z. T. Görcs, G. Sétáló, I. Lengvári, B. Flerkó, S. Vigh, and A. V. Schally (1983) Ultrastructural characteristics of immunolabelled, corticotropin releasing factor (CRF)-synthesizing neurons in the rat brain. Cell Tissue Res. 229: 191-196.

Liposits, Z., W. K. Paull, G. Sétáló, and S. Vigh (1985) Evidence for local corticotropin releasing factor (CRF)-immunoreactive neuronal circuits in the paraventricular nucleus of the rat hypothalamus. Histochemistry $83: 5-16$.

LuQui, I. J., and C. A. Fox (1976) The supraoptic nucleus and the supraopticoneurohypophyseal tract in the monkey (Macaca mulatta). J. Comp. Neurol. 168: 7-40.

Mason, W. T., Y. W. Ho, and G. I. Hatton (1984) Axon collaterals of supraoptic neurones: Anatomical and electrophysiological evidence for their existence in the lateral hypothalamus. Neuroscience 11:169182.

Milhaud, M., and G. D. Pappas (1968) Cilia formation in the adult cat brain after pargyline treatment. J. Cell Biol. 37: 599-609.

Morest, D. K. (1969) The growth of dendrites in the mammalian brain. Z. Anat. Entwickl. (Gesch.) 128: 290-317.

Palay, S. L. (1961) Structural peculiarities of the neurosecretory cells in the preoptic nucleus of the goldfish, Carassius auratus. Anat. Rec. 139: 262.

Piekut, D. T. (1983) Ultrastructural characteristics of vasopressincontaining neurons in the paraventricular nucleus of the hypothalamus. Cell Tissue Res. 234: 125-134.
Polenov, A. L., and J. I. Senchik (1966) Synapses on neurosecretory cells of the supra-optic nucleus in white mice. Nature 211: 14231424.

Ramón y Cajal, S. (1894) Algunas contribuciones al concimento de los ganglios del encefalo. III. Hipofisis. An. Soc. Esp. Hist. Rat. 2 Ser. $23: 195-237$.

Randle, J. C. R., C. W. Bourque, and L, P. Renaud (1986) Serial reconstruction of lucifer yellow-labeled supraoptic nucleus neurons in perfused rat hypothalamic cxplants. Neuroscience $\overline{1} \overline{7}: 4 \overline{5} 3-46 \overline{7}$.

Reaves, T. A., Jr., and J. N. Hayward (1981) Dye=marked paraven= tricular neuroendocrine celis in vivo in cat hypothalamus. Neurosci. Lett. $25: 263=267$.

Rechardt, L. (1969) Ultrastructure of the supraoptic nucleus of normal and dehydrated rats. Acta Physiol. Scand 329: 1=79.

Rho, J.-H., and L. W. Swanson (1987) Neuroendocrine CRF motoneurons: Intrahypothalamic axon terminals shown with a new retrograde-Lucifer-immuno method. Brain Res. 436: 143-147.

Sawchenko, P. E., and L. W. Swanson (1981) A method for tracing biochemically defined pathways in the central nervous system using combined fluorescence retrograde transport and immunothistochemical techniques. Brain Res. 210: 31-51.

Sawchenko, P. E., and L. W. Swanson (1982a) The organization of noradrenergic pathways from the brainstem to the paraventricular and supraoptic nuclei in the rat. Brain Res. Rev. 4: 275-325.

Sawchenko, P. E., and L. W. Swanson (1982b) Immunohistochemical identification of neurons in the paraventricular nucleus of the hypothalamus that project to the medulla or to the spinal cord in the rat. J. Comp. Neurol. 205: 260-272.

Sawchenko, P. E., L. W. Swanson, and W. W. Valc (1984) Corticotropin releasing factor: Co-expression within distinct subsets of oxytocin-, vasopressin-, and neurotensin-immunoreactive neurons in the hypothalamus of the male rat. Neuroscience 4: 1118-1129.

Sawchenko, P. E., L. W. Swanson, J. Rivier, and W. W. Vale (1985) The distribution of growth hormone-releasing factor (GRF)-immunoreactivity in the central nervous system of the rat: An immunohistochemical study using antisera directed against rat hypothalamic GRF. J. Comp. Neurol. 237: 100-115.

Selye, H., and C. E. Hall (1943) Further studies concerning the action of sodium chloride on the pituitary. Anat. Rec. 86: 579-583.

Sherlock, D. A., P. M. Field, and G. Raisman (1975) Retrograde transport of horseradish peroxidase in the magnocellular neurosecretory system of the rat. Brain Res. 88: 403-414.

Silverman, A. J., A. Hou-You, and E. A. Zimmerman (1983) Ultrastructural studies of vasopressin neurons of the paraventricular nucleus of the hypothalamus using a monoclonal antibody to vasopressin: Analysis of synaptic input. Neuroscience 9: 141-155.

Sofroniew, M. V., and W. Glasmann (1981) Golgi-like immunoperoxidase staining of hypothalamic magnocellular neurons that contain vasopressin, oxytocin or neurophysin in the rat. Neuroscience 6:619643.

Stubblefield, E., and B. R. Brinkley (1966) Cilia formation in Chinese hamster fibroblasts in vitro as a response to colcemid treatment. J. Cell Biol. 30: 645-652.

Suarez, I., B. Fernandez, M. A. Perez-Batista, and I. Azcoitia (1985) Ciliated neurons in the paraventricular nuclei in old hamsters. J. Submicrosc. Cytol. 17: 351-356.

Swanson, L. W., and H. G. J. M. Kuypers (1980) The paraventricular nucleus of the hypothalamus: Cytoarchitectonic subdivisions and the organization of projections to the pituitary, dorsal vagal complex and spinal cord as demonstrated by retrograde fluorescence double-labeling methods. J. Comp. Neurol. 194: 555-570.

Swanson, L. W., and P. E. Sawchenko (1983) Hypothalamic integration: Organization of the paraventricular and supraoptic nuclei. Annu. Rev. Neurosci. 6: 275-325.

Swanson, L. W., P. E. Sawchenko, A. Bérod, B. K. Hartman, K. B. Helle, and D. E. Van Orden (1981) An immunohistochemical study of the organization of catecholaminergic cells and terminal fields in the paraventricular and supraoptic nuclei of the hypothalamus. $J$. Comp. Neurol. 196: 271-285.

Swanson, L. W., P. E. Sawchenko, J. Rivier, and W. W. Vale (1983) Organization of ovine corticotropin-releasing factor immunoreactive cells and fibers in the rat brain: An immunohistochemical study. Neuroendocrinology $36: 161-178$.

Swanson, L. W., P. E. Sawchenko, and R. W. Lind (1986) Regulation of multiple peptides in CRF parvocellular neurosecretory neurons: Implications for the stress response. Prog. Brain Res., 68: 169-190. 
Swanson, L. W., P. E. Sawchenko, R. W. Lind, and J.-H. Rho (1987) The CRF motoneuron: Differential peptide regulation in neurons with possible synaptic, paracrine, and endocrine outputs. Ann. NY Acad. Sci. 512: 12=23.

Szentágothai, J., B. Flerkó, B. Mess, and B. Halảsz (1968) Hypothalamic Control of the Anterior Pituitary. An Experimental=Morphological Study. Akađémiāi Kiadó, Budapest.
Van Den Pol, A. N. (1982) The magnocellular and parvocellular para= ventricular nucleus of the rat: Intrinsic organization. J. Comp. Neurol. 206: $317-345$.

Zambrano, D, and E. de Robertis (1966) The secretory cycle of su= praoptic neurons in the rat. A structural-functional correlation. Z. Zellforsch. 73: 414-431. 